\title{
Gray Matter Growth Is Accompanied by Increasing Blood Flow and Decreasing Apparent Diffusion Coefficient during Childhood
}

\author{
(D)N.D. Forkert, (D)M.D. Li, (D)R.M. Lober, and (D).W. Yeom
}

\begin{abstract}
BACKGROUND AND PURPOSE: Normal values of gray matter volume, cerebral blood flow, and water diffusion have not been established for healthy children. We sought to determine reference values for age-dependent changes of these parameters in healthy children.
\end{abstract}

MATERIALS AND METHODS: We retrospectively reviewed MR imaging data from 100 healthy children. Using an atlas-based approach, age-related normal values for regional CBF, apparent diffusion coefficient, and volume were determined for the cerebral cortex, hippocampus, thalamus, caudate, putamen, globus pallidus, amygdala, and nucleus accumbens.

RESULTS: All gray matter structures grew rapidly before the age of 10 years and then plateaued or slightly declined thereafter. The ADC of all structures decreased with age, with the most rapid changes occurring prior to the age of 5 years. With the exception of the globus pallidus, CBF increased rather linearly with age.

CONCLUSIONS: Normal brain gray matter is characterized by rapid early volume growth and increasing CBF with concomitantly decreasing ADC. The extracted reference data that combine CBF and ADC parameters during brain growth may provide a useful resource when assessing pathologic changes in children.

ABBREVIATION: $A S L=$ arterial spin-labeling

$A^{\prime}$ birth, brain volume is approximately one-third that of a healthy adult brain and undergoes rapid growth during the first 3 months. ${ }^{1}$ By the age of 1 year, brain volume has already doubled in size. ${ }^{2}$ Initially, most hemispheric growth relates to an increase in gray matter volume, ${ }^{3}$ thought to reflect synapse formation occurring earliest in the primary motor and sensory cortices and later in the prefrontal cortex, ${ }^{4}$ directing a posterior-toanterior pattern of hemispheric white matter maturation. ${ }^{5}$ After the first few years, white matter volume increases at a higher rate during the rest of the childhood, ${ }^{6}$ while synaptic pruning occurs concurrently in the gray matter. ${ }^{4}$

Received December 10, 2015; accepted after revision February 8, 2016.

From the Department of Radiology and Hotchkiss Brain Institute (N.D.F.), University of Calgary, Calgary, Alberta, Canada; Department of Radiology (M.D.L., K.W.Y.), Lucile Packard Children's Hospital, Stanford University, Palo Alto, California; and Department of Neurosurgery (R.M.L.), Dayton Children's Hospital, Boonshoft School of Medicine, Dayton, Ohio.

This work was supported by a Brain and Behavior Center Award in Pediatric Neurosciences at Stanford Lucile Packard Children's Hospital.

Please address correspondence to Nils Daniel Forkert, PhD, Department of Radiology and Hotchkiss Brain Institute, University of Calgary, HSC Building, Rm 2913,

3330 Hospital Drive NW, Calgary, Alberta T2N 4N1, Canada; e-mail: nils.forkert@ucalgary.ca

Indicates article with supplemental on-line photo.

http://dx.doi.org/10.3174/ajnr.A4772

Compared with macrostructural analysis using image-based volume extraction, diffusion-weighted MR imaging can be used to probe microstructural changes, including myelination patterns ${ }^{7,8}$ and white matter connectivity, ${ }^{9}$ and has also shown utility for brain tumor characterization ${ }^{10}$ and metabolic diseases. ${ }^{11}$ Various studies have examined apparent diffusion coefficient changes of white matter in children. ${ }^{12-14}$ However, at present, the ADC of the gray matter, notably at the cortical level, is not welldocumented.

While volumetric and diffusion analysis can be used to probe macro- and microstructural changes, respectively, arterial spinlabeling (ASL) cerebral blood flow is increasingly used clinically to obtain advanced physiologic information. ${ }^{15-18}$ ASL may be particularly useful in the pediatric population because it does not require intravenous contrast or ionizing radiation. However, only a few studies have examined ASL CBF changes in children. ${ }^{19,20}$

These few studies have included ASL CBF of unsedated healthy term and preterm neonates ${ }^{21}$ or infants 3-5 months of age. ${ }^{22}$ Apart from these 2 studies, normal values have also been assessed as part of studies investigating CBF changes across the whole life span with only limited data from children ${ }^{20}$ or for feasibility analysis of ASL imaging, also using only a limited number of healthy children. $^{19}$ 
At present, no study has examined the CBF of a healthy pediatric cohort across the age spectrum. Therefore, the goal of this study was to extract and establish age-related CBF values in gray matter along with corresponding volume and diffusion metrics.

\section{MATERIALS AND METHODS \\ Study Cohort}

All children presenting for evaluation by a 3T MR imaging system at our children's hospital from May 2010 to October 2013 were retrospectively reviewed after approval by the Stanford University institutional review board (protocol 28674). The study cohort included patients 4 months to 18 years of age with no known neurologic, neurocognitive, or developmental deficits, who had a normal appearing brain MRI protocol that included ASL and DWI datasets. All MR imaging brain studies with normal findings were additionally reviewed and confirmed by at least 1 pediatric neuroradiologist with a Certificate of Added Qualification (K.W.Y. or P. Barnes both with $>7$ years of dedicated experience). Patients who had brain MR imaging with any focal intensity on FLAIR or other sequences, cysts, wide Sylvian fissures, or other nonspecific structural appearances were excluded. Patients with dental braces/metal artifacts and motion-degraded or non-diagnostic-quality imaging were also excluded.

A thorough chart review was performed (M.D.L.) to identify any disease history. Examples of clinical reasons for obtaining MR imaging included syncope, nausea, family history of aneurysm or cancers, scalp nevus, isolated facial lesions (eg, orbital or glabellar dermoid) without associated syndromes or intracranial extension, orbital strabismus, cholesteatoma of the ear, isolated headaches, sinus disease or inflammatory nasal obstruction, and short stature that was considered familial without intracranial or endocrine abnormality.

Patients with any systemic or non-central nervous system diseases (eg, diseases of the renal, gastrointestinal, cardiac systems), cancers, history of prematurity, phacomatoses, genetic or syndromic conditions, epilepsy, migraines, hearing loss, hemorrhage, vascular lesions (aneurysm, AVM, fistula, or steno-occlusive disease of the CNS or elsewhere), acute or recent infection and fever of unknown origin, prior radiation or chronic medical therapy, or endocrine symptoms/laboratory abnormalities were excluded. Patients were also screened for all psychiatric and abnormal behavioral conditions (attention deficit/hyperactivity disorder, autism, psychosis) and were excluded if present.

Finally, subjects with insufficient data or registration results (see below) were also excluded from the final analysis.

\section{Imaging Methods}

All subjects had brain MR imaging obtained at 3T (Discovery 750; GE Healthcare, Milwaukee, Wisconsin) using an 8-channel head coil. Pseudocontinuous ASL MR imaging was performed using the technique described by Dai et al. ${ }^{23}$ Briefly, this vendor-supplied ASL was performed using a pseudocontinuous labeling period of $1500 \mathrm{~ms}$, followed by a 1500-ms postlabel delay. Wholebrain images were acquired with a 3D background-suppressed fast spin-echo stack-of-spirals method. Multiarm spiral imaging was used, with 8 arms and 512 points acquired on each arm (bandwidth $=62.5 \mathrm{kHz}$ ), yielding a $3-\mathrm{mm}^{2}$ in-plane spatial reso- lution and a 4-mm section thickness. A high level of background suppression was achieved using 4 separate inversion pulses spaced around the pseudocontinuous labeling pulse. The acquisition time for this sequence is approximately 5 minutes, which also includes proton-density images required for CBF quantification. For a graphic setup of the ASL, the sagittal image following the 3-plane localizer was used for alignment. Postprocessing was performed using an automated reconstruction procedure using the microsphere methodology described by Buxton et al. ${ }^{24}$ Other pseudocontinuous ASL MR imaging parameters were $\mathrm{TR}=4632$ $\mathrm{ms}, \mathrm{TE}=10.5 \mathrm{~ms}, \mathrm{FOV}=24 \mathrm{~cm}$, and $\mathrm{NEX}=3$.

Additionally, echo-planar DWI was performed using $\mathrm{TR}=$ $1500 \mathrm{~ms}, \mathrm{TE}=37 \mathrm{~ms}$, flip angle $=90^{\circ}$, acceleration factor $=2$, in-plane resolution $=0.94 \mathrm{~mm}^{2}$, acquisition matrix $=128 \times 128$ interpolated to a $256 \times 256$ matrix, 44 sections with 4 -mm section thickness, no skip, FOV $=24 \mathrm{~cm}, 2$ diffusion-weightings of $b=0$ $\mathrm{s} / \mathrm{mm}^{2}$ and $b=1000 \mathrm{~s} / \mathrm{mm}^{2}$, with diffusion gradients acquired in 3 directions averaged for the latter.

\section{Image Processing}

The image-processing pipeline used for extraction of quantitative values of regional brain volume, $\mathrm{ADC}$, and $\mathrm{CBF}$ is illustrated in Fig 1. The complete image-processing pipeline used was custom-developed and implemented in $\mathrm{C}++$ using the Insight Segmentation and Registration Toolkit (ITK, http://www.itk. org/). In the first step of this pipeline, the ASL CBF and $b=1000$ $\mathrm{s} / \mathrm{mm}^{2}$ DWI dataset were registered to the corresponding T2weighted DWI dataset $\left(b=0 \mathrm{~s} / \mathrm{mm}^{2}\right)$ using rigid transformations, linear interpolation, and maximization of the mutual information. ${ }^{25}$ The registered DWI datasets were then used to calculate the corresponding ADC map for each subject using the StejskalTanner equation. ${ }^{26}$

Finally, the Montreal Neurological Institute-152 brain atlas ${ }^{27}$ was registered to each $b=0 \mathrm{~s} / \mathrm{mm}^{2}$ DWI dataset using a concatenated affine and nonlinear spline transformation. The affine transformation was determined using a linear interpolation and maximization of the mutual information metric. The calculated affine transformation was used to prealign the atlas to the patient anatomy in terms of initialization of a b-spline transformation, which was used for the fine nonlinear alignment of the Montreal Neurological Institute atlas to the $b=0 \mathrm{~s} / \mathrm{mm}^{2}$ DWI dataset. This b-spline transformation was optimized using linear interpolation and maximization of the mutual information metric.

All registrations were performed within a multiresolution registration framework with 3 levels, while the calculation of the mutual information similarity metric was restricted in all cases to the brain mask of the $b=0 \mathrm{~s} / \mathrm{mm}^{2}$ DWI dataset, which was generated using the method described by Forkert et al. ${ }^{28}$ Two experienced observers (N.D.F., K.W.Y.) checked all registration results to ensure suitable data and registration quality.

For quantitative assessment of volume, ADC, and CBF of the different gray matter brain regions, the resulting nonlinear spatial deformation field for alignment of the Montreal Neurological Institute atlas to each subject was used to warp the Harvard-Oxford subcortical brain regions, as defined in the Montreal Neurological Institute atlas space, to each $b=0 \mathrm{~s} / \mathrm{mm}^{2} \mathrm{DWI}$ dataset by applying nearest neighbor interpolation. 


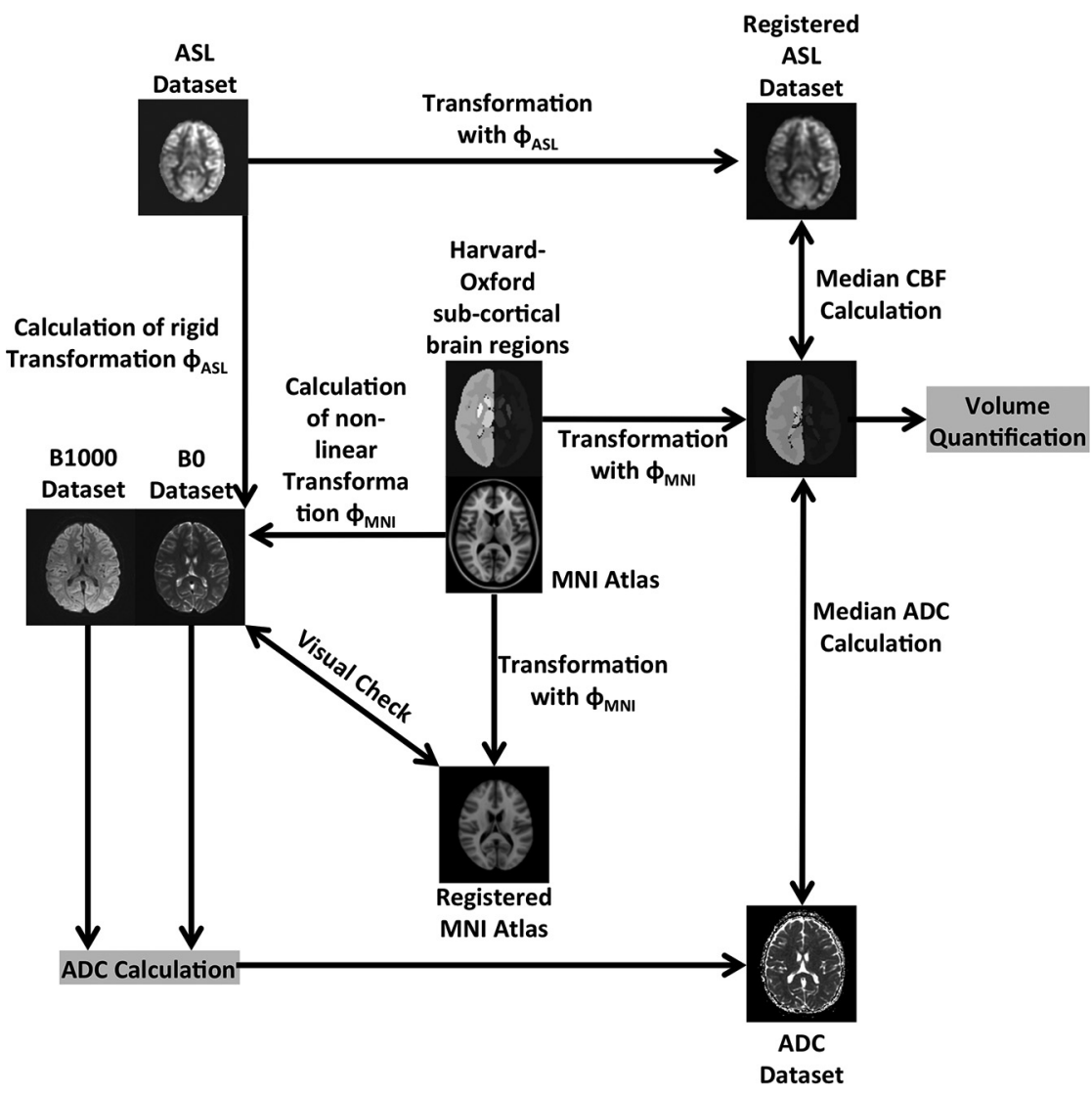

FIG 1. Illustration of the image-processing pipeline used for determination of the age-dependent volumetric, $A D C$, and $C B F$ normal values.

\begin{tabular}{cc} 
Age distribution of neurologically healthy patients \\
\hline Age Range (yr) & No. of Children \\
\hline $0-2$ & 14 \\
$2-4$ & 22 \\
$4-6$ & 8 \\
$6-8$ & 7 \\
$8-10$ & 4 \\
$10-12$ & 16 \\
$12-14$ & 7 \\
$14-16$ & 13 \\
$16-18$ & 9 \\
Total & 100 \\
\hline
\end{tabular}

After registration of all datasets, volume, median ADC, and median $\mathrm{CBF}$ values were determined for each subject within the following 8 gray matter brain structures: cerebral cortex, hippocampus, thalamus, caudate, putamen, globus pallidus, amygdala, and nucleus accumbens.

\section{Statistical Analysis}

The volume for each structure was averaged between the 2 corresponding structures in the left and right hemispheres, while the median $\mathrm{ADC}$ and median $\mathrm{CBF}$ values were determined for each region combined for the left and right hemispheres.

The quantile local piecewise regression analysis described by Sakov et $\mathrm{al}^{29}$ was used in this work to determine the age-related 5th, 10th, 25th, 50th, 75th, 90th, and 95th quantile curves individually for each brain structure and for the 3 parameters: volume, ADC, and CBF. The parameters for the local piecewise re- gression analysis were kept identical for all plots generated. More specifically, a window size of 30 points, $95 \%$ overlap between the windows, Gaussian smoothing, and a polynomial degree of 2 were used.

Each scatterplot and corresponding regression curves were inspected for qualitative description of the age-related changes.

In our study, intravenous propofol sedation was performed for all children 3 months to 6 years of age. After 10 years of age, no patients received sedation. Between 6 and 9 years of age, there were variable rates of sedation. In this age group, comparison of sedated and nonsedated groups was conducted using the Welch 2-tailed $t$ test to test for significant differences between children with and without sedation.

All statistics were calculated using the R statistical software package of The R Foundation of Statistical Computing (Version 3.2.2; www.r-project.org).

\section{RESULTS}

One hundred healthy subjects (age range, 4 month to 18 years; 39 males) met the inclusion criteria and were included in the study. The specific number of children in each age group is summarized in the Table. Overall, all structures analyzed exhibited similar patterns of the age-dependent distribution of regional brain volume, $\mathrm{ADC}$, and $\mathrm{CBF}$ values with different levels. Figure 2 exemplarily displays the age-dependent distribution of regional brain volume, $\mathrm{ADC}$, and CBF values in the thalamus. The corresponding graphs for all gray matter structures analyzed in this work can be found in On-line Fig 1.

\section{Gray Matter Volume}

In general, the volume increased with age in all gray matter structures. The volumetric increase with age was nonlinear and was highest from birth to approximately 8-10 years of age. Thereafter, volumes reached a stable plateau or displayed a slight decrease.

\section{ADC of the Gray Matter}

Median ADC values of the gray matter declined with increasing age. The highest median ADC values occurred in the first 5 years of childhood. During this period, an exponential decay of ADC values was observed in all gray matter structures. After 5 years of age, ADC continued to decrease in a rather linear fashion with increasing age. Overall, median ADC values in the cerebral cortex and hippocampus were about $10 \%$ higher than in the other gray matter regions investigated. This finding was consistent across all age groups. 

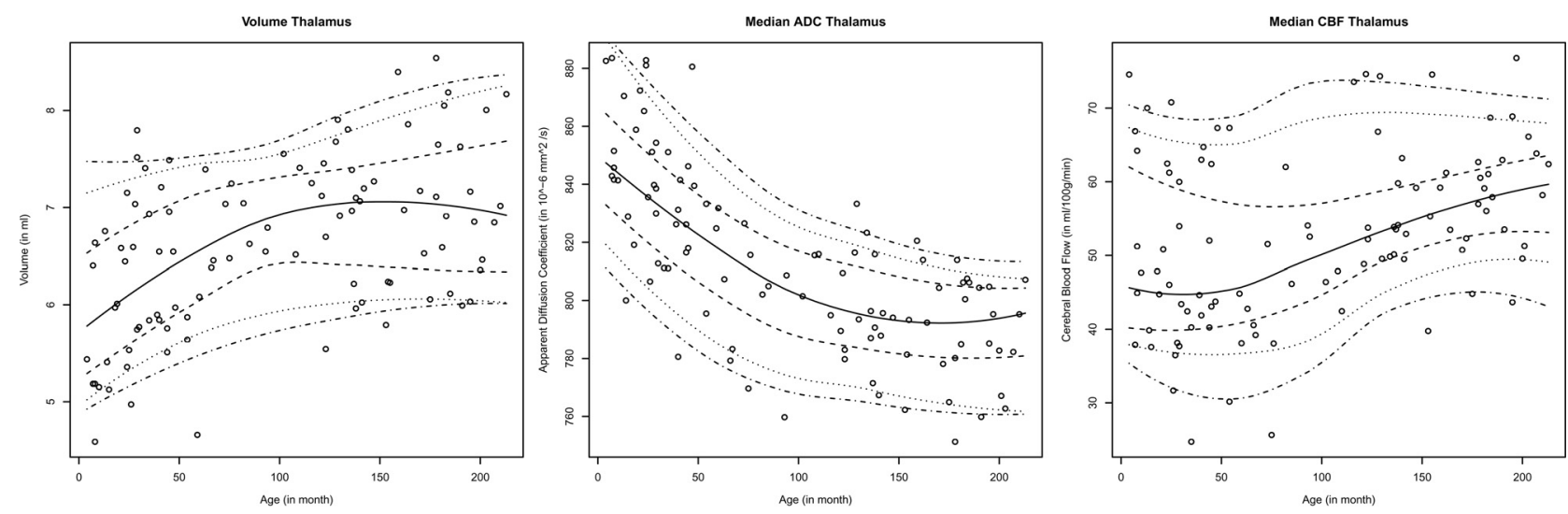

FIG 2. Graphic representation of the age-dependent volumetric, $A D C$, and CBF normal values for the thalamus illustrated using the $5 \%, 10 \%$, $25 \%, 50 \%, 75 \%, 90 \%$, and $95 \%$ centile curves.

\section{CBF of the Gray Matter}

Cerebral blood flow was more variable than volume and ADC, particularly in the first 5 years of childhood. Unlike the rapid volume and $\mathrm{ADC}$ changes in the first 5 years of life, $\mathrm{CBF}$ increased rather linearly with age, with decreased variability at older ages. CBF in all gray matter structures increased with age, except for the globus pallidus, which was stable throughout childhood. The degree of CBF increase did not differ considerably among the caudate, thalamus, putamen, nucleus accumbens, and amygdala, but a smaller degree of CBF increase was found for the hippocampus, and a larger $\mathrm{CBF}$ increase, for the cerebral cortex with age.

\section{Sedated versus Nonsedated Children}

The comparison of sedated ( $n=7$; mean age, 7.6 years) and nonsedated children ( $n=4$; mean age, 7.9 years) revealed no significant CBF differences in any brain region studied (Welch 2-tailed $t$ test, $P>.01$; Bonferroni-adjusted significance level $=$ $.005)$.

\section{DISCUSSION}

Gray matter CBF increased with age, except in the globus pallidus. Notably, the cerebral cortex, amygdala, and nucleus accumbens showed the highest $\mathrm{CBF}$ increase. These CBF changes were accompanied by a progressive ADC decrease and volumetric increase for all gray matter structures, with ADC stabilizing at about 10-12 years and peak volume occurring at around 8-12 years, with a slight decrease thereafter. To our knowledge, this is the first study to investigate age-related changes of gray matter $\mathrm{CBF}$ accompanied by corresponding volume and ADC values in a single cohort of neurologically healthy children throughout childhood and adolescence.

Our volumetric results are consistent with prior studies of healthy subjects that showed an overall increase in cortical gray matter volume in the preadolescent years and a decline in the postadolescent period. ${ }^{30}$ Volumetric analysis for infancy and early childhood remains sparse, but our results are also consistent with the growth pattern described in a study of 28 children 1 month to 10 years of age, in whom a rapid growth pattern was followed by a more gradual increase. ${ }^{31}$ A more recent study that focused on infants (3-13 months of age) also observed an increasing volume of all gray matter regions with some regionally different growth patterns. ${ }^{32}$
While volume increased, the ADC of the gray matter declined rapidly, with a fast exponential component in the first few years, which then stabilized in early adolescence. These findings likely reflect the combined effects of neuronal development, myelination, and decrease in water content ${ }^{33}$ and associated MR imaging signal changes ${ }^{34,35}$ that rapidly occur in the early years of development. Potential contributions of iron-deposition that decrease $\mathrm{T} 2$ relaxation time may also be considered, particularly in the deep gray nuclei, which has been observed in children older than 4 years of age and in adolescents. ${ }^{36}$

Although various studies have reported ADC changes of cerebral white matter in children, ${ }^{12-14}$ gray matter structures have remained relatively unexplored. We observed a steep decline with an exponential component in early childhood with a decreasing trend continuing into later childhood, consistent with results of prior ROI-based studies in selected deep gray regions (caudate, putamen, globus pallidus). ${ }^{37,38}$

Compared with volume and ADC changes, a wider variation in $\mathrm{CBF}$ values was seen across age. In addition, median $\mathrm{CBF}$ values and the magnitude of increase varied among the gray matter regions. Previous studies have described a close relationship between $\mathrm{CBF}$ and the cerebral metabolic rate ${ }^{39-41}$; and in a study of cerebral metabolism in 29 children ( 5 days to 15 years of age) using ${ }^{18} \mathrm{~F}-\mathrm{FDG}$ positron-emission tomography, a similar pattern of highest proportional increase in metabolic activity was seen in the cerebral cortex compared with the other brain regions. ${ }^{42}$

We observed a gradual increase in CBF in all gray matter regions, except for the globus pallidus, throughout childhood and adolescence, which differs from a previous ASL CBF study that described a relatively stable-to-decreased CBF between 4 and 12 years of age, followed by a sharp decline in adolescence ${ }^{20}$ in 23 children aged 4-19 years. One possible explanation might be differences in postlabel delay periods. Because the ASL tracer lifetime is dependent on the longitudinal relaxation time of blood, which is similar to the transport time from the labeling position to the tissue (arterial transit time), a shorter postlabel delay period of $1000 \mathrm{~ms}$ used in the study by Biagi et $\mathrm{al}^{20}$ may be insufficient for complete delivery of labeled blood to the tissue, a potential limitation when assessing adolescents with slower arterial transit time compared with younger children. ${ }^{43,44}$ The present data in our study were obtained from a pseudocontinuous ASL technique, 
which has been shown to have a superior labeling efficiency, ${ }^{23}$ signal-to-noise ratio, and reproducibility, ${ }^{45}$ and is thus preferred over other ASL methods. We also used a postlabel delay of 1500 ms recommended by the current guidelines of the International Society for Magnetic Resonance in Medicine for clinical imaging of the pediatric brain. ${ }^{46}$

Biagi et $\mathrm{al}^{20}$ also observed increased gray matter CBF in pediatric patients receiving halogenated anesthesia relative to awake patients, which was rather similar to those receiving only intravenous propofol. A review of adult functional imaging studies noted that propofol was associated with decreased CBF, determined by PET, in all brain regions in multiple studies. ${ }^{47}$ Thus, a disproportionate number of younger children requiring halogenated anesthesia could have affected their results. For example, an ASL study in 4 patients with Moyamoya disease found that halogenated anesthesia (sevoflurane) was associated with consistently higher global gray matter CBF. ${ }^{48}$ In our study, intravenous propofol sedation, with or without mask induction using a halogenated anesthetic, was performed for all children 3 months to 6 years of age. Between 6 and 9 years of age, there were variable rates of sedation. The statistical analysis of children with and without sedation in this age range showed no significant differences. This could possibly be explained by a balancing effect of increased CBF with halogenated anesthesia and decreased CBF with propofol. ${ }^{20}$ Thus, no correction was necessary in this study.

Brain development has been shown to be associated with regional changes in the glucose cerebral metabolic rate ${ }^{42}$ and CBF. ${ }^{49}$ Thus, continued increases in ASL CBF during childhood and adolescence may reflect a more protracted period of functional development and maturation. While global cerebral volume has been shown to peak at 14.5 years for boys and 11.5 years for girls, changes in cortical gray matter volume are more complex and have shown regional heterochronicity. ${ }^{50}$ For example, in a study of 145 subjects 4-21 years of age, the frontal and parietal lobes showed an earlier peak at 11-12 years of age, while maximal temporal gray matter volumes occurred at 16-17 years of age, and the occipital lobes had a linear increase through 20 years of age without signs of decline. ${ }^{30}$ Previous studies have also reported periods of postnatal rapid brain growth up to 20 years of age based on electroencephalography energy metrics in the $\alpha$ frequencies. ${ }^{51,52}$ A spike in CBF was observed preceding these stages of brain growth, suggesting a higher energy requirement during these periods, ${ }^{53}$ a pattern also seen in the rat cerebral cortex that has shown increased vascular sprouting shortly before rapid growth stages. $^{54}$

Individual differences in brain growth spurts may also explain variations of $\mathrm{CBF}$ observed in the present study to some degree. While the definitive reasons for relatively stable CBF in the globus pallidus and a slower rate of CBF increase in the hippocampus compared with the other brain regions analyzed remain unknown, it is possible that these regions demonstrate different rates of growth or metabolism. For example, a morphometric analysis of infants 3-13 months of age showed a slower growth rate in certain brain regions, such as the globus pallidus and hippocampus, relative to the whole brain, despite an overall increase in volume in absolute values. ${ }^{32}$

We recognize certain limitations of this study. For example, for our analysis, the adult Montreal Neurological Institute atlas was registered to the pediatric brain. While registration of a pediatric atlas might be more accurate for this purpose, different brain atlases generated by using different age ranges and subjects (eg, described by Fonov et $\mathrm{al}^{55}$ ) would be necessary, potentially making the results not directly comparable. Therefore, we decided to use the well-established Montreal Neurological Institute adult brain atlas with the available Harvard-Oxford atlas brain regions for this purpose so that the same reference was used for each subject to analyze CBF, ADC, and volume data metrics. To minimize any effects of suboptimal registration results, we performed further quality control, including visual inspection by our team members with knowledge of brain imaging and anatomy. Within this context, 22 subjects not part of the 100 subjects described in this study were excluded from the final analysis due to insufficient registration of the Montreal Neurological Institute brain atlas.

In addition, the $b=0 \mathrm{~s} / \mathrm{mm}^{2}$ DWI datasets were used as a reference for atlas registration. These datasets do not offer the same high spatial resolution compared with T1-weighted datasets usually used for this purpose, which limits the precision of the extracted regional brain volumes, especially for small structures such as the amygdala.

However, although our goal was to demonstrate CBF changes against volume and ADC across various age groups for various brain regions rather than to define precise metrics for volume, the growth patterns found are well in line with previous findings, suggesting reasonable registration results.

Finally, the regional brain volumes were averaged between corresponding left and right hemispheric structures, while median ADC and CBF values were calculated for each combined corresponding left and right hemisphere brain structure. This procedure was selected to decrease the influence of noise in the data, especially for the small structures such as the amygdala and nucleus accumbens. When analyzed separately, no significant difference between the age-related trends of corresponding left and right brain structures was found for the regional brain volume, $\mathrm{ADC}$, and CBF metrics.

\section{CONCLUSIONS}

Normal gray matter is characterized by rapid early volume growth and increasing $\mathrm{CBF}$, with concomitantly decreasing ADC. The extracted reference data that combine $\mathrm{CBF}$ and $\mathrm{ADC}$ parameters during brain growth may provide a useful resource when assessing pathologic changes in children.

\section{ACKNOWLEDGMENTS}

The authors would like to thank Patrick Barnes, Department of Pediatric Neuroradiology, Stanford University, for his support in reviewing the MR imaging brain studies used in this work.

\section{REFERENCES}

1. Holland D, Chang L, Ernst TM, et al. Structural growth trajectories and rates of change in the first 3 months of infant brain development. JAMA Neurol 2014;71:1266-74 CrossRef Medline

2. Gilmore JH, Lin W, Prastawa MW, et al. Regional gray matter growth, sexual dimorphism, and cerebral asymmetry in the neonatal brain. J Neurosci 2007;27:1255-60 CrossRef Medline

3. Knickmeyer RC, Gouttard S, Kang C, et al. A structural MRI study of 
human brain development from birth to 2 years. J Neurosci 2008;28: 12176-82 CrossRef Medline

4. Huttenlocher PR, Dabholkar AS. Regional differences in synaptogenesis in human cerebral cortex. J Comp Neurol 1997;387:167-78 Medline

5. Sampaio CS, Truwit CL. Myelination in the developing brain. In: Nelson CA, Luciana M, eds. Handbook of Developmental Cognitive Neuroscience. Cambridge, Massachusetts: MIT Press; 2001:35-44

6. Dubois J, Dehaene-Lambertz G, Kulikova S, et al. The early development of brain white matter: a review of imaging studies in fetuses, newborns and infants. Neuroscience 2014;276:48-71 CrossRef Medline

7. Loh KB, Ramli N, Tan LK, et al. Quantification of diffusion tensor imaging in normal white matter maturation of early childhood using an automated processing pipeline. Eur Radiol 2012;22:1413-26 CrossRef Medline

8. Uda S, Matsui M, Tanaka C, et al. Normal development of human brain white matter from infancy to early adulthood: a diffusion tensor imaging study. Dev Neurosci 2015;37:182-94 CrossRef Medline

9. Alcauter S, Lin W, Smith JK, et al. Development of thalamocortical connectivity during infancy and its cognitive correlations. J Neurosci 2014;34:9067-75 CrossRef Medline

10. Löbel U, Sedlacik J, Reddick WE, et al. Quantitative diffusionweighted and dynamic susceptibility-weighted contrast-enhanced perfusion MR imaging analysis of T2 hypointense lesion components in pediatric diffuse intrinsic pontine glioma. AJNR Am J Neuroradiol 2011;32:315-22 CrossRef Medline

11. Dyke JP, Voss HU, Sondhi D, et al. Assessing disease severity in late infantile neuronal ceroid lipofuscinosis using quantitative MR diffusion-weighted imaging. AJNR Am J Neuroradiol 2007;28:1232-36 CrossRef Medline

12. Löbel U, Sedlacik J, Güllmar D, et al. Diffusion tensor imaging: the normal evolution of ADC, RA, FA, and eigenvalues studied in multiple anatomical regions of the brain. Neuroradiology 2009;51: 253-63 CrossRef Medline

13. Engelbrecht V, Scherer A, Rassek M, et al. Diffusion-weighted MR imaging in the brain in children: findings in the normal brain and in the brain with white matter diseases. Radiology 2002;222:410-18 CrossRef Medline

14. Rollins NK, Glasier P, Seo Y, et al. Age-related variations in white matter anisotropy in school-age children. Pediatr Radiol 2010;40: 1918-30 CrossRef Medline

15. Chen J, Licht DJ, Smith SE, et al. Arterial spin labeling perfusion MRI in pediatric arterial ischemic stroke: initial experiences. $J$ Magn Reson Imaging 2009;29:282-90 CrossRef Medline

16. Yeom KW, Lober RM, Alexander A, et al. Hydrocephalus decreases arterial spin-labeled cerebral perfusion. AJNR Am J Neuroradiol 2014;35:1433-39 CrossRef Medline

17. Yeom KW, Lober RM, Barnes PD, et al. Reduced cerebral arterial spin-labeled perfusion in children with neurofibromatosis type 1. AJNR Am J Neuroradiol 2013;34:1823-28 CrossRef Medline

18. Yeom KW, Mitchell LA, Lober RM, et al. Arterial spin-labeled perfusion of pediatric brain tumors. AJNR Am J Neuroradiol 2014;35: 395-401 CrossRef Medline

19. Wang J, Licht DJ, Jahng GH, et al. Pediatric perfusion imaging using pulsed arterial spin labeling. J Magn Reson Imaging 2003;18:404-13 CrossRef Medline

20. Biagi L, Abbruzzese A, Bianchi MC, et al. Age dependence of cerebral perfusion assessed by magnetic resonance continuous arterial spin labeling. J Magn Reson Imaging 2007;25:696-702 CrossRef Medline

21. Miranda MJ, Olofsson K, Sidaros K. Noninvasive measurements of regional cerebral perfusion in preterm and term neonates by magnetic resonance arterial spin labeling. Pediatr Res 2006;60:359-63 CrossRef Medline

22. Duncan AF, Caprihan A, Montague EQ, et al. Regional cerebral blood flow in children from $\mathbf{3}$ to $\mathbf{5}$ months of age. AJNR Am J Neuroradiol 2014;35:593-98 CrossRef Medline
23. Dai W, Garcia D, de Bazelaire C, et al. Continuous flow-driven inversion for arterial spin labeling using pulsed radio frequency and gradient fields. Magn Reson Med 2008;60:1488-97 CrossRef Medline

24. Buxton RB, Frank LR, Wong EC, et al. A general kinetic model for quantitative perfusion imaging with arterial spin labeling. Magn Reson Med 1998;40:383-96 CrossRef Medline

25. Wells WM 3rd, Viola P, Atsumi H, et al. Multi-modal volume registration by maximization of mutual information. Med Image Anal 1996;1:35-51 CrossRef Medline

26. Stejskal EO, Tanner JE. Spin diffusion measurements: spin echoes in the presence of a time-dependent field gradient. J Chem Phys 1965; 42:288-92 CrossRef

27. Mazziotta JC, Toga AW, Evans A, et al. A probabilistic atlas of the human brain: theory and rationale for its development-the International Consortium for Brain Mapping (ICBM). Neuroimage 1995; 2:89-101 CrossRef Medline

28. Forkert ND, Cheng B, Kemmling A, et al. ANTONIA perfusion and stroke: a software tool for the multi-purpose analysis of MR perfusion-weighted datasets and quantitative ischemic stroke assessment. Methods Inf Med 2014;53:469-81 CrossRef Medline

29. Sakov A, Golani I, Lipkind D, et al. High-throughput data analysis in behavior genetics. Ann Appl Stat 2010;4:743-63 CrossRef

30. Giedd JN, Blumenthal J, Jeffries NO, et al. Brain development during childhood and adolescence: a longitudinal MRI study. Nat Neurosci 1999;2:861-63 CrossRef Medline

31. Matsuzawa J, Matsui M, Konishi T, et al. Age-related volumetric changes of brain gray and white matter in healthy infants and children. Cereb Cortex 2001;11:335-42 CrossRef Medline

32. Choe MS, Ortiz-Mantilla S, Makris N, et al. Regional infant brain development: an MRI-based morphometric analysis in 3 to 13 month olds. Cereb Cortex 2013;23:2100-17 CrossRef Medline

33. Dobbing J, Sands J. Quantitative growth and development of human brain. Arch Dis Child 1973;48:757-67 CrossRef Medline

34. Barkovich AJ, Kjos BO, Jackson DE J., et al. Normal maturation of the neonatal and infant brain: MR imaging at 1.5 T. Radiology 1988; 166:173-80 CrossRef Medline

35. Autti T, Raininko R, Vanhanen SL, et al. MRI of the normal brain from early childhood to middle age, II: age dependence of signal intensity changes on T2-weighted images. Neuroradiology 1994;36: 649-51 CrossRef Medline

36. Thomas LO, Boyko OB, Anthony DC, et al. MR detection of brain iron. AJNR Am J Neuroradiol 1993;14:1043-48 Medline

37. Mukherjee P, Miller JH, Shimony JS, et al. Normal brain maturation during childhood: developmental trends characterized with diffusion-tensor MR imaging. Radiology 2001;221:349-58 CrossRef Medline

38. Pal D, Trivedi R, Saksena S, et al. Quantification of age- and genderrelated changes in diffusion tensor imaging indices in deep grey matter of the normal human brain. J Clin Neurosci 2011;18:193-96 CrossRef Medline

39. Raichle ME. Behind the scenes of functional brain imaging: a historical and physiological perspective. Proc Natl Acad Sci U S A 1998; 95:765-72 CrossRef Medline

40. Jueptner M, Weiller C. Review: does measurement of regional cerebral blood flow reflect synaptic activity? Implications for PET and fMRI. Neuroimage 1995;2:148-56 CrossRef Medline

41. Sokoloff $\mathrm{L}$. Localization of functional activity in the central nervous system by measurement of glucose utilization with radioactive deoxyglucose. J Cereb Blood Flow Metab 1981;1:7-36 CrossRef Medline

42. Chugani HT, Phelps ME, Mazziotta JC. Positron emission tomography study of human brain functional development. Ann Neurol 1987;22:487-97 CrossRef Medline

43. Petersen ET, Mouridsen K, Golay X. The QUASAR reproducibility study, part II: results from a multi-center arterial spin labeling testretest study. Neuroimage 2010;49:104-13 CrossRef Medline

44. Bokkers RP, van der Worp HB, Mali WP, et al. Noninvasive MR imaging of cerebral perfusion in patients with a carotid artery stenosis. Neurology 2009;73:869-75 CrossRef Medline 
45. Chen Y, Wang DJ, Detre JA. Test-retest reliability of arterial spin labeling with common labeling strategies. J Magn Reson Imaging 2011;33:940-49 CrossRef Medline

46. Alsop DC, Detre JA, Golay X, et al. Recommended implementation of arterial spin-labeled perfusion MRI for clinical applications: a consensus of the ISMRM perfusion study group and the European consortium for ASL in dementia. Magn Reson Med 2015;73:102-16 CrossRef Medline

47. Song XX, Yu BW. Anesthetic effects of propofol in the healthy human brain: functional imaging evidence. J Anesth 2015;29:279-88 CrossRef Medline

48. Venkatraghavan L, Poublanc J, Bharadwaj S, et al. Noninvasive measurement of cerebral blood flow under anesthesia using arterial spin labeling MRI: a pilot study. J Neurosurg Anesthesiol 2015 Sep 20. [Epub ahead of print] Medline

49. Chiron C, Raynaud C, Mazière B, et al. Changes in regional cerebral blood flow during brain maturation in children and adolescents. J Nucl Med 1992;33:696-703 Medline
50. Lenroot RK, Gogtay N, Greenstein DK, et al. Sexual dimorphism of brain developmental trajectories during childhood and adolescence. Neuroimage 2007;36:1065-73 CrossRef Medline

51. Epstein HT. EEG developmental stages. Dev Psychobiol 1980;13: 629-31 CrossRef Medline

52. Hudspeth WJ, Pribram KH. Stages of brain and cognitive maturation. J Educ Psychol 1990;82:881-84 CrossRef

53. Epstein HT. Stages of increased cerebral blood flow accompany stages of rapid brain growth. Brain Dev 1999;21:535-39 CrossRef Medline

54. Rowan RA, Maxwell DS. Patterns of vascular sprouting in the postnatal development of the cerebral cortex of the rat. Am J Anat 1981; 160:247-55 CrossRef Medline

55. Fonov V, Evans AC, Botteron K, et al; Brain Development Cooperative Group. Unbiased average age-appropriate atlases for pediatric studies. Neuroimage 2011;54:313-27 CrossRef Medline 